\title{
Synthesis, structure and properties of poly(ether-urethane)s synthesized using a tri-functional oxypropylated glycerol as a polyol
}

\author{
Janusz Datta $^{1} \cdot$ Paulina Kosiorek $^{1} \cdot$ Marcin Włoch $^{1}$
}

Received: 5 January 2016/ Accepted: 26 October 2016/Published online: 8 November 2016

(C) The Author(s) 2016. This article is published with open access at Springerlink.com

\begin{abstract}
The main aim of this work was to obtain poly(ether-urethane)s using tri-functional polyoxyalkylene polyol (Rokopol G1000), which introducing the chemical cross-links into the structure of polyurethanes. Poly(etherurethane)s were prepared using two-step method, called prepolymer method, which involves in the first step the reaction of 4,4'-diphenylmethane diisocyanate (MDI) and tri-functional polypropylene glycol glycerol triether polyol. In the second step, prepolymer chains were extended by using: 1,6-hexanediol, 1,4-butanediol in the mixture with poly(ethylene glycol) and poly(ethylene glycol). The prepolymer chains extending was realized at three different molar ratios of $\mathrm{NCO}$ groups (presented in prepolymer) to $\mathrm{OH}$ groups (presented in chain extender), i.e., $0.95,1.00$ or 1.05. The influence of chain extender type on the chemical structure, selected mechanical properties and thermomechanical properties of the obtained poly(ether-urethane)s was investigated. The results showed that applying different types of chain extenders results in obtaining materials with diversified mechanical properties, but very similar thermal stability. The performance of obtained poly(etherurethane)s is mostly affected by the chemical cross-links, which were introduced into soft segments by tri-functional polyetherol.
\end{abstract}

Keywords Poly(ether-urethane)s · Tri-functional polyetherol $\cdot$ Mechanical properties $\cdot$ TG $\cdot$ Dynamic mechanical thermal analysis (DMA)

Janusz Datta

janusz.datta@pg.gda.pl

1 Department of Polymers Technology, Faculty of Chemistry, Gdańsk University of Technology, G. Narutowicza Str. 11/12, 80-233 Gdańsk, Poland

\section{Introduction}

Polyurethanes are synthesized through the reaction of di- or poly-isocyanates, high molecular weight polyols and low molecular weight chains extenders $[1,2]$, but it is also possible to synthesis of PUs by non-isocyanate route [3, 4]. Currently, polymers are prepared from components, which are derived from petroleum [5, 6]. Renewable substances proposed for the synthesis of polymers are, for example, vegetable oils (e.g., linseed oil, sunflower oil, palm oil, cotton oil, soybean oil, tung oil, cashew nut oil [5-8]), glycerol and its derivatives $[9,10]$, terpenes $[11]$ and rosin $[12,13]$. The bio-based components, which can be used as a polyols in the synthesis of polyurethanes, are, for example, castor oil [14], polyricinoleate diol [15], hydroxylated soybean oil $[6,16]$, hydroxylated hemp seed oil [17] and polyglycerols [18]. Bio-based trends are also visible in the synthesis of isocyantes [19].

Polyurethanes are synthesized mainly in the form of linear elastomers and soft or rigid foams, but some investigations are focused on the chemically cross-linked polyurethanes. The chemical cross-links can be introduced into the structure of polyurethanes through hard segments or soft segments [20-22]. It was found that chemical crosslinks in the hard segments destroyed the crystallinity of the hard segments and restricted the mobility of the soft segments, but improving the thermal stability of the hard segments [21]. Mentioned earlier bio-based substances (especially polyglycerol or vegetable oil-based polyols) introducing generally chemical cross-links into the structure of polyurethanes.

Plant oils are mixtures, which containing esters of glycerin and saturated or unsaturated fatty acids, and can be used as intermediates for the synthesis of polyols. The chemical modification of vegetable oils involves, for 
example, epoxidation of unsaturated bonds followed by hydroxylation [6, 23]. Vegetable oil offers the intrinsic properties, i.e., reduced toxicity, low cost, high purity and renewable nature $[6,14,24]$. Moreover, chemical modified vegetable oils, as well as glycerol, can be useful in the synthesis of multifunctional polyols. Rigid polyurethane foams can be produced using especially multifunctional bio-based polyols as, for example, polyglycerol [25]. Biopolyols from crude glycerol can be obtained by thermochemical conversion process. The bio-polyols, produced by $\mathrm{X}$. Luo et al. [26], have suitable properties for the production of PU foams, e.g., hydroxyl number of around $481 \mathrm{mgKOH} \mathrm{g}^{-1}$. Sorbitol is a polyhydric alcohol monomer, which can be used in the polyols and the polyesters synthesis, and contains primary and secondary hydroxyl groups. Isorbitol can also be directly used as a polyol in the synthesis of polyurethanes [27]. L. Gustini et al. obtained hydroxy-functional polyesters based on sorbitol in a controlled way by enzymatic polycondensation, and obtained products can be used in the synthesis of polyurethane coatings. Obtained from mentioned functional polyesters coatings exhibit good solvent resistance and mechanical properties [28]. A. Anand et al. [29] obtained polyol by the reaction of sorbitol, 1,2,3,6-tetrahydrophthalic anhydride, adipic acid, and diethylene glycol and zinc acetate as a catalyst. Obtained hydroxyl-functional products were used to prepare the polyurethane coatings.

In the presented work to the synthesis of polyurethanes was used tri-functional polyether polyol based on the oxypropylated glycerol. Mentioned polyol has trade name Rokopol G1000 and is produced by PCC Rokita in Poland. This polyol can be used as a component for the synthesis of polyurethane elastomers, single spray foam, coatings, adhesives, impregnates and varnishes. The presence of three primary hydroxyl groups permits to obtain chemical cross-linked polyurethanes.

In this work, the influence of tri-functional polyetherol (Rokopol G1000) and different chain extenders (i.e., 1,6hexanediol, 1,4-butanediol in the mixture with poly(ethylene glycol) and poly(ethylene glycol) separately) on the chemical structure, mechanical properties (i.e., tensile properties, hardness, abrasion resistance and rebound resilience) and dynamic mechanical properties (i.e., storage modulus, loss modulus and damping factor vs. temperature) was studied. Moreover, thermal properties (by differential scanning calorimetry, DSC) and thermal stability (by thermogravimetric analysis, TG) were determined. It was found that applying different types of chain extenders results in obtaining materials with diversified properties, but the most important component, which affecting the structure and properties of obtained PUs, is tri-functional polyol, which introducing the chemical cross-links (in the soft segments) into the structure of obtained poly(etherurethane)s.

\section{Experimental}

\section{Synthesis of poly(ether-urethane)s}

Poly(ether-urethane)s were synthesized by two-step method called prepolymer method. In the first step, prepolymer was synthesized by the reaction of tri-functional polypropylene glycol glycerol triether polyol Rokopol G1000, PCC Rokita S.A., $M_{\mathrm{w}}=1000, \quad$ LOH $=155$ $165 \mathrm{mgKOH} \mathrm{g}^{-1}$ ) with $4,4^{\prime}$-diphenylmethane diisocyanate (MDI, BorsodChem, Hungary). The reaction was carried out at $80{ }^{\circ} \mathrm{C}$ for $2 \mathrm{~h}$ (Fig. 1). The percentage of the free isocyanate groups in the obtained ether-urethane prepolymer was determined by titration method (in accordance to ISO 14896 standard) and was equal to $8.06 \%$.

In the second step, prepolymer chains were extended by using: (1) poly(ethylene glycol) with average molecular weight $300 \mathrm{~g} \mathrm{~mol}^{-1}$ PEG300 (Sigma-Aldrich), (2) mixture of mentioned poly(ethylene glycol) with 1,4-butanediol BDO (Brenntag, Poland) or (3) 1,6-hexanediol HDO (Avantor Performance Materials S.A., Poland). The chains extending step was realized at three different molar ratios of NCO groups (presented at the end of prepolymer chains) to $\mathrm{OH}$ groups (presented in the chemical structure of chain extenders), i.e., $0.95,1.00$ or 1.05 . The reaction of prepolymer with mentioned chain extenders was realized without using a catalyst due to high reaction rate connected with significant increasing of the reaction mixture viscosity. In the next step, prepared polyurethanes were seasoned at $100{ }^{\circ} \mathrm{C}$ for $24 \mathrm{~h}$ in laboratory oven, which permit to complete the reaction between $\mathrm{NCO}$ and $\mathrm{OH}$ groups. The codes of obtained polyurethanes, with description of their meaning, are presented in Table 1. The calculated content of the hard and the soft segments is presented in Table 2 . Hard segments (HSs) are composed from 4,4'-methylene diphenyl diisocyanates and 1,6-hexanediol or 1,4-butanediol. Soft segments (SSs) are composed from Rokopol G1000 polyol and/or poly(ethylene glycol).

\section{Testing methods}

Chemical structure of obtained poly(ether-urethane)s was determined by means of Fourier Transform Infrared Spectroscopy (FTIR) with using Nicolet FTIR 8700 spectrophotometer (Thermo Electron Co.). Spectra were registered at room temperature for wave numbers between 500 and $4500 \mathrm{~cm}^{-1}$ at nominal resolution $4 \mathrm{~cm}^{-1}$. Each spectrum was acquired with 64 scans. The measurements were 
Fig. 1 Synthesis of etherurethane prepolymer<smiles>O=C=Nc1ccc(Cc2ccc(NC(=O)OC(OC(=O)Nc3ccc(Cc4ccc(N=C=O)cc4)cc3)OC(=O)Nc3ccc(Cc4ccc(N=C=O)cc4)cc3)cc2)cc1</smiles>

Table 1 Chain extenders and $\mathrm{NCO} / \mathrm{OH}$ molar ratio during prepolymer chains extending in the case of obtained poly(ether-urethane)s

\begin{tabular}{lcc}
\hline Code of material & Chain extender & $\begin{array}{l}\text { NCO/OH molar ratio during } \\
\text { extending of prepolymer chains }\end{array}$ \\
\hline PU-PEG-0.95 & Poly(ethylene glycol) & 0.95 \\
PU-PEG-1.0 & & 1.0 \\
PU-PEG-1.05 & Mixture of 1,4-butanediol (20 mass\%) with & 1.05 \\
PU-PEG/BDO-0.95 & poly(ethylene glycol) (80 mass\%) & 0.95 \\
PU-PEG/BDO-1.0 & & 1.0 \\
PU-PEG/BDO-1.05 & 1,6-hexanediol & 1.05 \\
PU-HDO-0.95 & & 0.95 \\
PU-HDO-1.0 & & 1.0 \\
PU-HDO-1.05 & & 1.05 \\
\hline
\end{tabular}

Table 2 Content of hard segments (HS) and soft segment (SS) in prepared poly(ether-urethane)s

\begin{tabular}{lll}
\hline Material code & Hard segments/mass\% & Soft segments/mass\% \\
\hline PU-PEG & 33.9 & 66.1 \\
PU-PEG/BDO & 36.9 & 63.1 \\
PU-HDO & 50.0 & 50.0
\end{tabular}

taken in the Department of Physical Chemistry at Gdańsk University of Technology.

The morphology of the cross sections of prepared materials was investigated using Scanning Electron Microscopy (SEM). Image of the cross sections of prepared materials was carried out under the desktop scanning electron microscope with accelerating voltage of $5 \mathrm{kV}$.

Static tensile properties (tensile strength and elongation at break) were measured using an universal testing machine Zwick/Roell Z020, with cross-head speed $100 \mathrm{~mm} \mathrm{~min}^{-1}$, according to ISO 527-2. The test samples were prepared in a standard dumbbell shape, and obtained results are averages of five independent tests.
Hardness was determined according to ISO 868 standard using an electronic Shore type A and D Durometer, and presented results are averages from random ten points in one specimen.

Elasticity (rebound resilience) was determined in accordance with ISO 4662 standard. Measurements were taken using a Schob pendulum, and obtained results are averages of ten independent tests.

Abrasion resistance of obtained polyurethanes was determined using Schopper-Schlobach instrument, and obtained results are presented as volume loss of the sample. For each prepared polyurethane materials, three independent tests were taken.

Density of synthesized polyurethane was measured with using an analytical balance RADWAG by hydrostatic method with using methanol as an immersion medium, according to ISO 2781. Measurements were taken at room temperature and were repeated five times for each prepared material.

Thermogravimetric analysis $(T G)$ was carried with using NETZSCH TG 209F3 Analyzer. The samples were heated at a rate $20{ }^{\circ} \mathrm{C} \mathrm{min}^{-1}$, from 50 to $600{ }^{\circ} \mathrm{C}$. TG 
<smiles>COCCOC(=O)Nc1ccc(Cc2ccc(NC(=O)OC(OC(=O)Nc3ccc(Cc4ccc(NC(=O)OCCOC)cc4)cc3)OC(=O)Nc3ccc(Cc4ccc(NC(=O)OCCOC)cc4)cc3)cc2)cc1</smiles>

Fig. 2 Synthesis of PU-PEG<smiles>O=C=Nc1ccc(Cc2ccc(NC(=O)OC(OC(=O)Nc3ccc(Cc4ccc(N=C=O)cc4)cc3)OC(=O)Nc3ccc(Cc4ccc(N=C=O)cc4)cc3)cc2)cc1</smiles><smiles>COCCCCOC(=O)Nc1ccc(Cc2ccc(NC(=O)OC(OC(=O)Nc3ccc(Cc4ccc(NC(=O)OCCOC)cc4)cc3)OC(=O)Nc3ccc(Cc4ccc(NC(=O)OCCOC)cc4)cc3)cc2)cc1</smiles>

Fig. 3 Synthesis of PU-PEG/BDO

measurements were realized under nitrogen atmosphere. The samples mass was around $5 \mathrm{mg}$.

Dynamic mechanical analysis (DMA) of obtained poly(ether-urethane)s was performed using DMA Q800 Analyzer (TA Instruments) according to ASTM D6045. Measurements were taken in a temperature range from -60 to $+120{ }^{\circ} \mathrm{C}$ at an operating frequency of $1 \mathrm{~Hz}$ and heating rate of $4{ }^{\circ} \mathrm{C} \mathrm{min}^{-1}$. The samples were $2 \mathrm{~mm}$ thick, $10 \mathrm{~mm}$ wide and $40 \mathrm{~mm}$ long. The variation of storage modulus, loss modulus and tangent delta versus temperature was determined.

Differential Scanning Calorimetry (DSC) was used to determine the glass transition temperature of soft segments. Measurements were taken by using a DSC 204 F1 Phoenix 
<smiles>COCCCCCCOC(=O)Nc1ccc(Cc2ccc(NC(=O)OC(OC(=O)Nc3ccc(Cc4ccc(NC(=O)OCCCCCCOC)cc4)cc3)OC(=O)Nc3ccc(Cc4ccc(NC(=O)OCCCCCCOC)cc4)cc3)cc2)cc1</smiles>

Fig. 4 Synthesis of PU-HDO

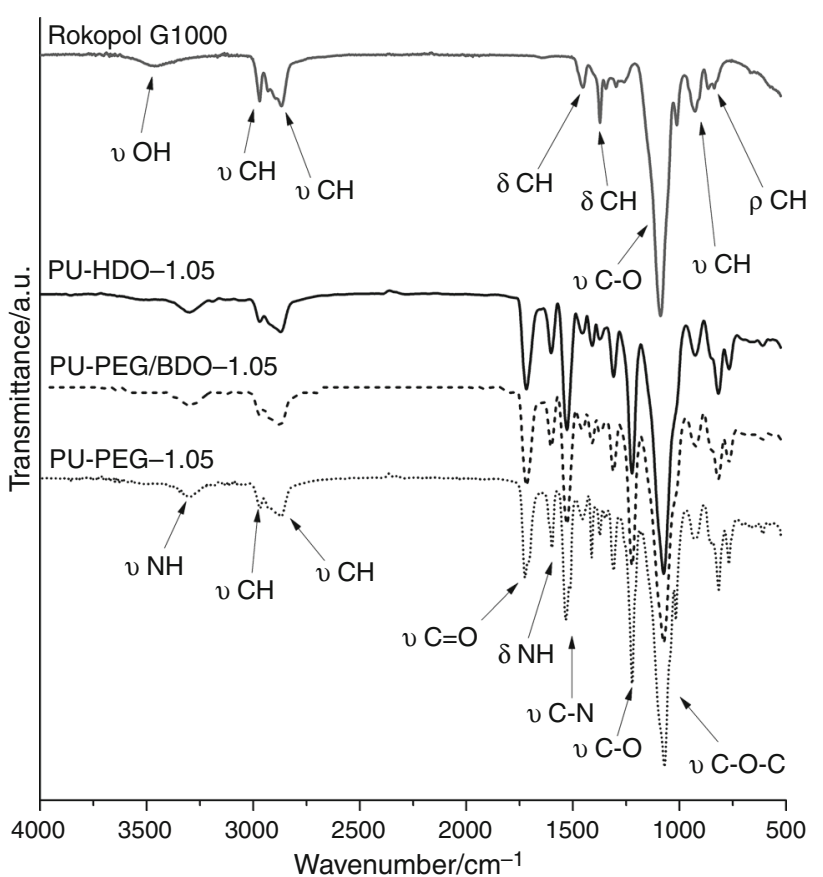

Fig. 5 FTIR spectra of polyetherol and prepared poly(etherurethane)s

Analyzer, equipped with a cooling system. The samples were heated at a rate of $20{ }^{\circ} \mathrm{C} \mathrm{min}{ }^{-1}$ from -80 to $200{ }^{\circ} \mathrm{C}$. In the first cycle, the thermal history of the sample was erased. It was then cooled down to $-80{ }^{\circ} \mathrm{C}$ at a cooling rate of $20{ }^{\circ} \mathrm{C} \min ^{-1}$, equilibrated for 5 min and then heated up to $200{ }^{\circ} \mathrm{C}$ at a rate of $20{ }^{\circ} \mathrm{C} \mathrm{min}{ }^{-1}$. All the measurements were taken under a dry nitrogen gas atmosphere, and the samples mass was around $5 \mathrm{mg}$.

\section{Result and discussion}

The chemical structure of polyetherol Rokopol G1000 and obtained pol(ether-urethane)s were confirmed by FTIR method (Fig. 5). The chemical structure of obtained poly(ether-urethane)s is presented earlier in Figs. 2-4. The analysis was performed for three selected samples, i.e., PUPEG-1.05, PU-PEG/BDO-1.05 and PU-HDO-1.05 (Fig. 2). The characteristic stretching vibrations of $\mathrm{N}-\mathrm{H}$ bond are presented at $3340 \mathrm{~cm}^{-1}$, which indicating the presence of hydrogen bonding in the all obtained polyurethanes (Fig. 5). In the range from 1680 to $1740 \mathrm{~cm}^{-1}$ is visible double peak connected with stretching vibration of $\mathrm{C}=\mathrm{O}$ groups presented in the structure of urethane bonds. The maximum observed at $1705 \mathrm{~cm}^{-1}$ is connected with hydrogen bonded carbonyl groups, while the maximum at $1725 \mathrm{~cm}^{-1}$ related to free carbonyl group [30]. The characteristic peak connected with stretching vibrations of $\mathrm{C}-\mathrm{N}$ bond appears at $1540 \mathrm{~cm}^{-1}$. The ether bonds $(\mathrm{C}-\mathrm{O}-\mathrm{C})$ stretching vibrations are presented at $1230 \mathrm{~cm}^{-1}$. FTIR spectra of all material samples displayed bands in the region from 2800 to $3000 \mathrm{~cm}^{-1}$, which are characteristic 
for the $\mathrm{C}-\mathrm{H}$ groups stretching vibrations. Piszczyk et al. [18] received similar FTIR spectra in their work, which was concerned at rigid polyurethane foams from a polyglycerol-based polyol.

The cross-sectional surfaces of the prepared poly(etherurethane)s are shown in Fig. 6-8. All polyurethanes have generally a smooth surface, but in some places voids are visible. Polyurethanes obtained using 1,6-hexanediol have the highest amount of air bubbles, and this is connected with the fastest gelation process [due to the lower chain length in comparison with poly(ethylene glycol)], which make degassing impossible.

The results from static tensile test are presented in Table 3. The highest tensile strength (25.6 MPa) was observed for material coded as PU-HDO-1.0, what is connected with applying 1,6-hexanediol as a chain
Fig. 6 Surface morphology PU-PEG-1.05

Fig. 7 Surface morphology of PU-PEG/BDO-1.05

Fig. 8 Surface morphology of PU-HDO-1.05
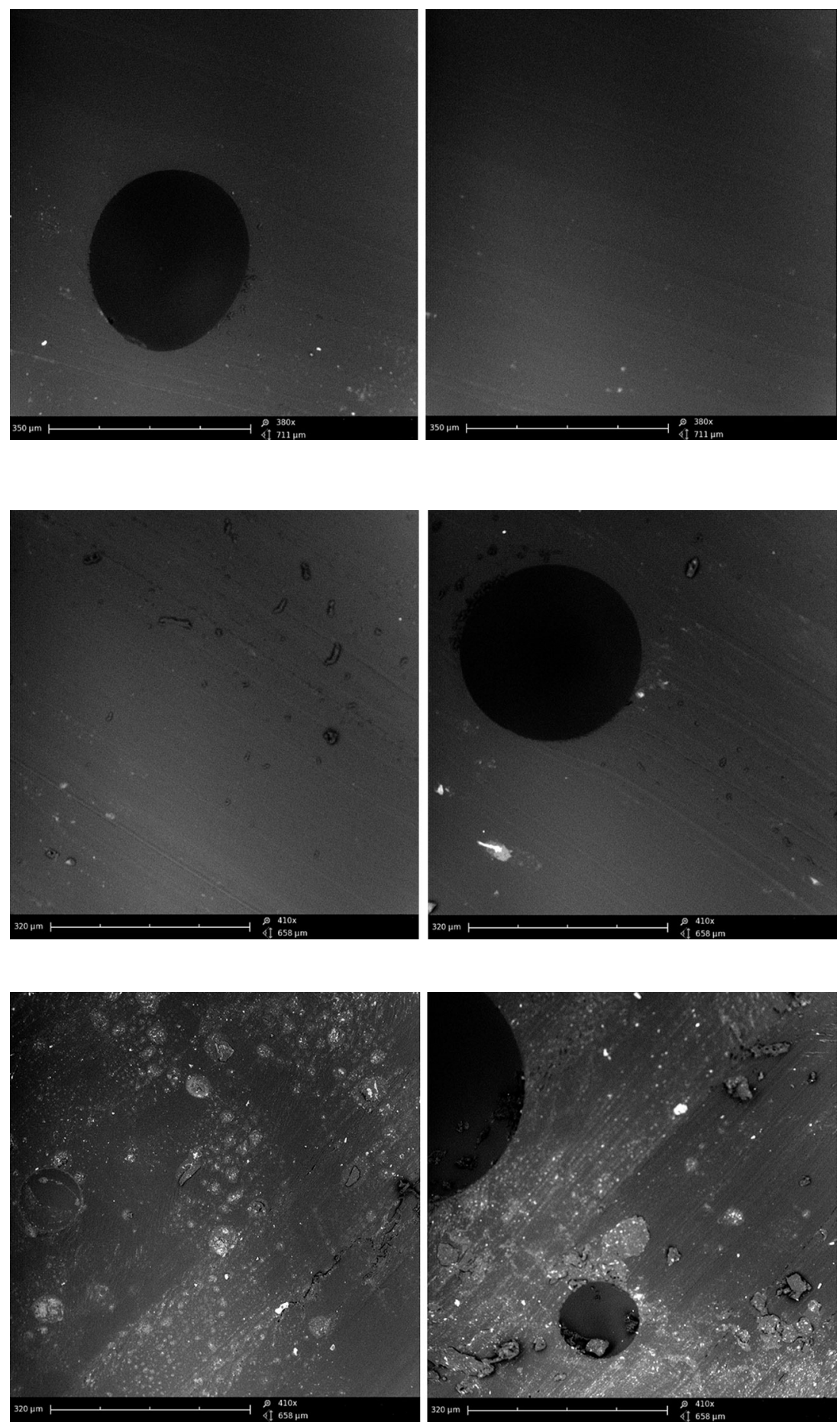
Table 3 Tensile strength and elongation at break of obtained poly(ether-urethane)s

\begin{tabular}{lcl}
\hline Code of material & Tensile strength/MPa & Elongation at break/\% \\
\hline PU-PEG-0.95 & $2.23 \pm 0.11$ & $109.11 \pm 8.16$ \\
PU-PEG-1.0 & $2.86 \pm 0.22$ & $106.79 \pm 22.04$ \\
PU-PEG-1.05 & $3.47 \pm 0.18$ & $122.95 \pm 9.57$ \\
PU-PEG/BDO-0.95 & $3.33 \pm 0.09$ & $147.11 \pm 6.03$ \\
PU-PEG/BDO-1.0 & $3.35 \pm 1.10$ & $106.58 \pm 43.94$ \\
PU-PEG/BDO-1.05 & $5.19 \pm 0.34$ & $143.71 \pm 7.88$ \\
PU-HDO-0.95 & $21.20 \pm 2.22$ & $32.97 \pm 15.22$ \\
PU-HDO-1.0 & $25.60 \pm 5.27$ & $23.25 \pm 5.62$ \\
PU-HDO-1.05 & $24.36 \pm 3.49$ & $29.70 \pm 16.33$ \\
\hline
\end{tabular}

extender. The low molecular weight chain extenders as 1,4butanediol or 1,6-hexanediol introduce hard segments into the structure of the final polyurethane, which resulted in high tensile strength and low elongation at break. In the case of the high molecular weight chain extender as a poly(ethylene glycol), the final material is more elastic and exhibits low tensile strength and high elongation at break, due to higher content of soft segments. So the lowest tensile strength was observed for materials coded as PU-PEG. Some improvement in tensile strength was obtained by applying mixture of PEG (80\%) with BDO (20 mass\%) as a chain extender, due to introduction of hard segments into structure of polyurethane by 1,4-butanediol. The PU-PEG materials have higher (around 110\%) elongation at break due to higher content of soft segments, than in the case of PU-HDO materials, which have elongation at break around $30 \%$. The restriction of polyurethane chain movements due to the presence of hard segments (introduced by MDI and HDO) connected with higher cross-link density resulted finally in lower elongation at break.

The hardness and rebound resilience of the prepared polyurethanes are presented in Table 4 . The results depend on the content of the soft and the hard segments in the

Table 4 Hardness and rebound resilience of obtained poly(etherurethane)s

\begin{tabular}{lll}
\hline Code of material & Hardness/ ${ }^{\circ} \mathrm{Sh} \mathrm{D}$ & Rebound resilience/\% \\
\hline PU-PEG-0.95 & $17.0 \pm 0.6$ & $1.4 \pm 0.5$ \\
PU-PEG-1 & $18.7 \pm 0.6$ & $1.8 \pm 0.4$ \\
PU-PEG-1.05 & $20.2 \pm 0.7$ & $2.4 \pm 0.5$ \\
PU-PEG/BDO-0.95 & $19.0 \pm 1.2$ & $2.6 \pm 0.7$ \\
PU-PEG/BDO-1 & $20.5 \pm 0.8$ & $6.0 \pm 0.1$ \\
PU-PEG/BDO-1.05 & $20.5 \pm 1.0$ & $7.9 \pm 0.6$ \\
PU-HDO-0.95 & $61.6 \pm 1.1$ & $31.1 \pm 1.0$ \\
PU-HDO-1 & $68.1 \pm 0.5$ & $28.4 \pm 1.6$ \\
PU-HDO-1.05 & $65.9 \pm 0.6$ & $30.0 \pm 1.3$ \\
\hline
\end{tabular}

polyurethane and $\mathrm{NCO} / \mathrm{OH}$ molar ratio during prepolymer chains extending. The hardness and rebound resilience decrease with increasing content of the soft segments, so the highest hardness and rebound resilience were observed in the case of polyurethanes synthesized with using 1,6hexanediol. As was mentioned earlier, high molecular weight chain extender as a poly(ethylene glycol) introduces soft segments in the structure of final polyurethane, in comparison with low molecular weight chain extenders as 1,4-butanediol or 1,6-hexanediol, which are connected with hard segments content. In the context of $\mathrm{NCO} / \mathrm{OH}$ molar ratio (at chain extending step), it can be seen that the optimal ratio of isocyanate groups to hydroxyl groups is equal 1.05 for the polyurethanes obtained using of PEG or PEG/BDO mixture, and 1.00 for materials synthesized with using $\mathrm{HDO}$ as a chain extender. The equimolar ratio $\mathrm{NCO} /$ $\mathrm{OH}$ in the case of 1,6-hexanediol is connected with higher accuracy of the molecular weight determination than in case of poly(ethylene glycol), which is characterized by average molecular weight.

The abrasion resistance and the density of the prepared poly(ether-urethane)s are presented in Table 5..Abrasion resistance of obtained materials is in the range from 0.194 to $0.366 \mathrm{~cm}^{3}$. The low molecular weight chain extenders, i.e., 1,6-hexanediol or 1,4-butanediol, introduce hard segment into the structure of the final poly(ether-urethane), which result in the lower volume loss during the abrasion test. The abrasion resistance decreases with increasing content of soft segments, introduced by poly(ethylene glycol), which was applied as a chain extender. The abrasion resistance of polyurethanes obtained using HDO is very similar for all used $[\mathrm{NCO}] /[\mathrm{OH}]$ molar ratios during the chain extending step.

The density of the produced polyurethanes is in the range from 1.135 to $1.147 \mathrm{~g} \mathrm{~cm}^{-3}$. Generally, it was observed that the densities of all studied materials are very similar and not affected by molar ratio of isocyanate groups

Table 5 Abrasion resistance and density of obtained poly(etherurethane)s

\begin{tabular}{lll}
\hline Code of material & Abrasion resistance $/ \mathrm{cm}^{3}$ & Density/g cm \\
\hline PU-PEG-0.95 & $0.366 \pm 0.011$ & $1.1473 \pm 0.0010$ \\
PU-PEG-1 & $0.233 \pm 0.056$ & $1.1465 \pm 0.0048$ \\
PU-PEG-1.05 & $0.259 \pm 0.017$ & $1.1454 \pm 0.0027$ \\
PU-PEG/BDO-0.95 & $0.264 \pm 0.015$ & $1.1365 \pm 0.0004$ \\
PU-PEG/BDO-1 & $0.294 \pm 0.054$ & $1.1372 \pm 0.0024$ \\
PU-PEG/BDO-1.05 & $0.342 \pm 0.085$ & $1.1417 \pm 0.0016$ \\
PU-HDO-0.95 & $0.237 \pm 0.018$ & $1.1354 \pm 0.0041$ \\
PU-HDO-1 & $0.242 \pm 0.019$ & $1.1370 \pm 0.0019$ \\
PU-HDO-1.05 & $0.237 \pm 0.010$ & $1.1372 \pm 0.0024$ \\
\hline
\end{tabular}


Fig. 9 TG curves of the poly(ether-urethane)s

Fig. 10 DTG curves of the poly(ether-urethane)s
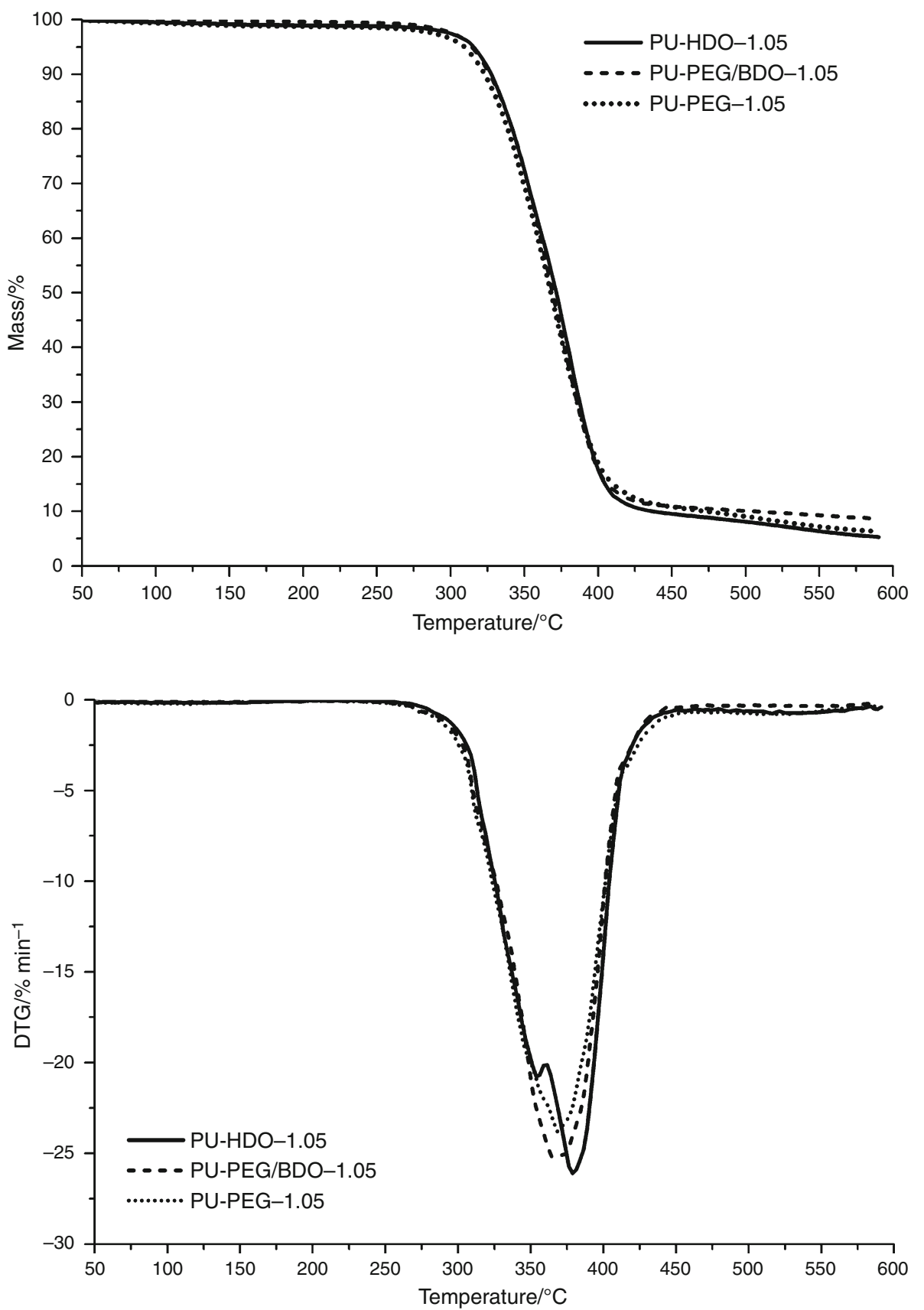

to hydroxyl groups during extending of urethane prepolymer chains.

The results of thermogravimetric analysis of prepared polyurethanes are shown in Fig. 9 (TG curves) and Fig. 10 (DTG curves). The characteristic temperatures of thermal decomposition are presented in Table 6. The thermal degradation of all synthesized polyurethanes begins at ca. $300{ }^{\circ} \mathrm{C}$, and this is connected with the thermal decomposition of urethane bonds. It is visible that the highest thermal stability is exhibited by PUs prepared with using 1,6-hexanediol as a chain extender, and it can be connected with the highest content of hard segments and the highest
Table 6 Thermal stability of obtained poly(ether-urethane)s

\begin{tabular}{lllll}
\hline Code of material & $T_{5} /{ }^{\circ} \mathrm{C}$ & $T_{10} /{ }^{\circ} \mathrm{C}$ & $T_{30} /{ }^{\circ} \mathrm{C}$ & $T_{50} /{ }^{\circ} \mathrm{C}$ \\
\hline PU-PEG-1.05 & 304.8 & 322.3 & 349.8 & 367.3 \\
PU-PEG/BDO-1.05 & 312.6 & 325.1 & 352.6 & 367.6 \\
PU-HDO-1.05 & 315.3 & 327.8 & 352.8 & 370.3 \\
\hline
\end{tabular}

cross-linking density of this material in comparison with other prepared materials. In Fig. 10 is visible the existence of two near maximum rates of thermal decomposition for PU-HDO, which are designated as $T_{\mathrm{d} 1}$ around $356{ }^{\circ} \mathrm{C}$ and 
$T_{\mathrm{d} 2}$ around $379{ }^{\circ} \mathrm{C}$, respectively. The first one is connected with hard segments, which content (50 mass\%) is higher than in the case of polyurethanes obtained using PEG and PEG/BDO as chain extenders. In the case of PU-PEG/BDO and PU-PEG, the thermal decomposition occurs with one stage, respectively, 367 and $373{ }^{\circ} \mathrm{C}$. Polyurethanes without phase separation are generally characterized by one-step thermal degradation, which involves simultaneous degradation of hard and soft segments, and it is observed commonly in the case of polyurethanes obtained using multifunctional components (like polyurethane foams) or polyurethanes with high content of soft segments [18, 31].

Generally, thermal degradation of polyurethanes occurs in two main steps. The first step is connected with thermal decomposition of the hard segments (i.e., urethane groups), and the second step involves thermal decomposition of the soft segments (i.e., ester and ether bonds) [32-34]. Thermal degradation mechanism of polyurethanes is a very complex process, especially in the case of polyurethanes obtained with using multifunctional components. The thermal
Fig. 11 Temperature dependence of tan delta of the poly(ether-urethane)s
Fig. 12 Temperature dependence of storage modulus of the poly(ether-urethane)s
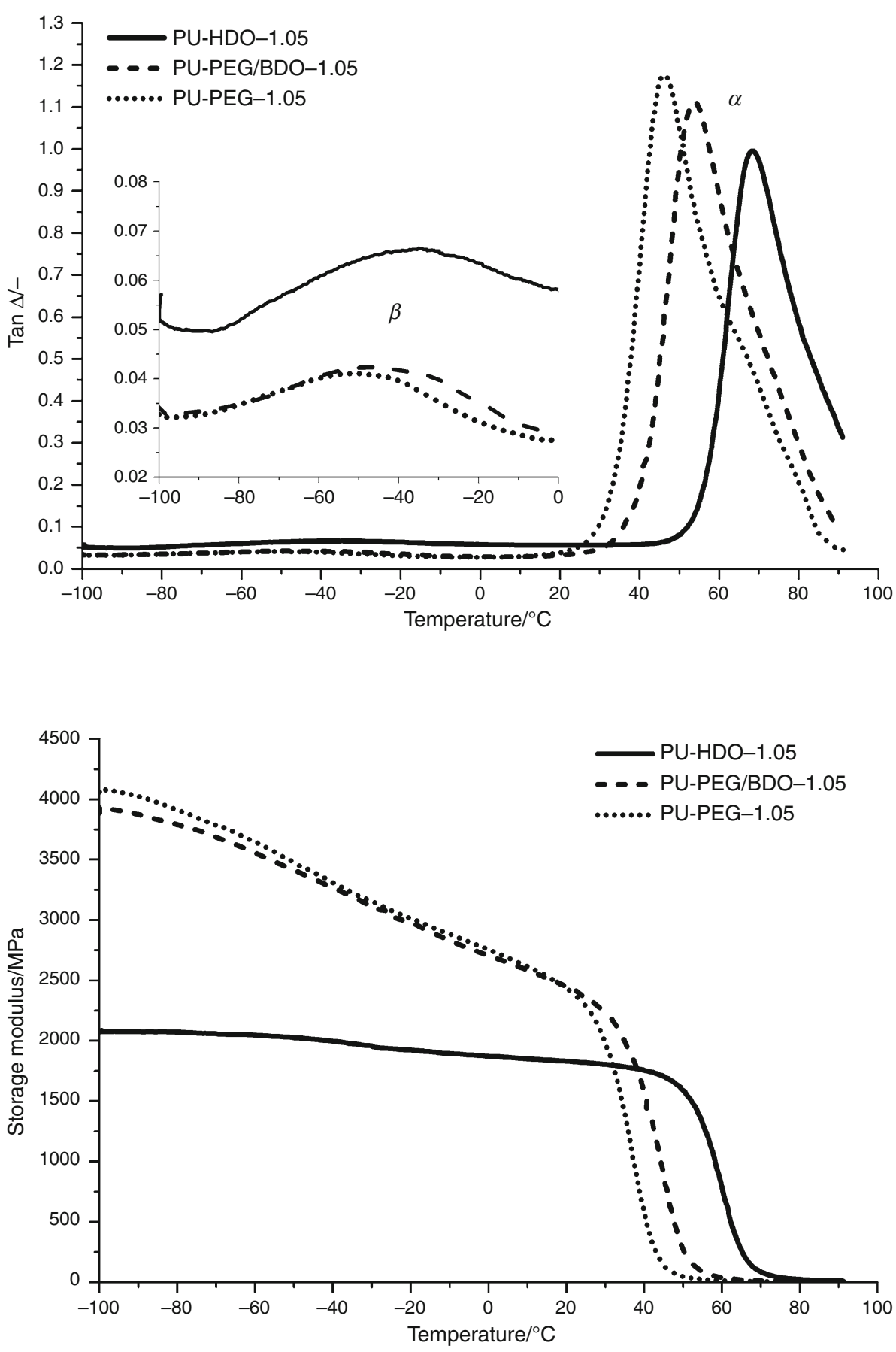
Fig. 13 Temperature dependence of loss modulus of the poly(ether-urethane)s

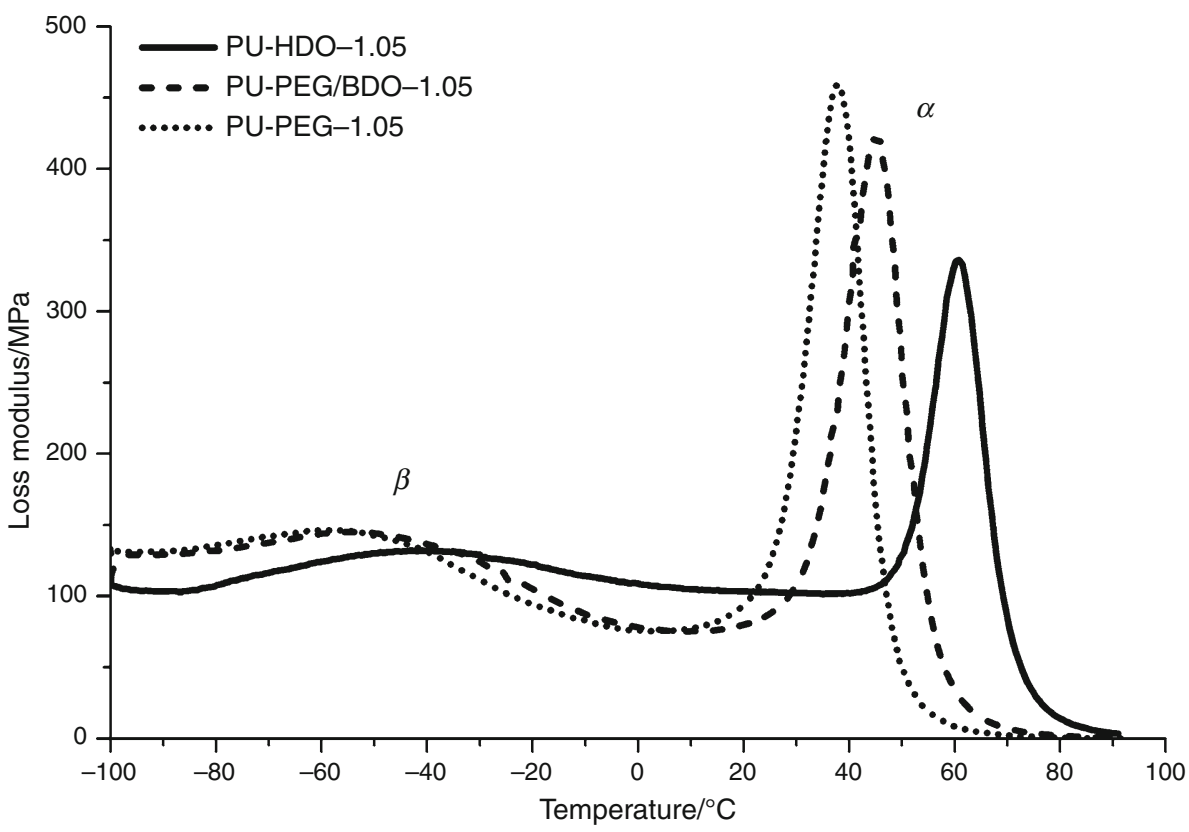

Table 7 Glass transition temperature of the soft segments for obtained poly(ether-urethane)s determined by DSC and DMA method

\begin{tabular}{lll}
\hline Code of material & $T_{\text {gSS DSC }} /{ }^{\circ} \mathrm{C}$ & $T_{\text {gSS DMA }} /{ }^{\circ} \mathrm{C}$ \\
\hline PU-PEG-1.05 & 15.3 & 45.8 \\
PU-PEG/BDO-1.05 & 19.7 & 53.7 \\
PU-HDO-1.05 & 37.3 & 68.7 \\
\hline
\end{tabular}

decomposition of urethane bonds was investigated by Dyer et al. [35-37], who studied the thermal degradation of the model urethanes (i.e., carbamates) and indicated three ways of the urethane linkage cleavage at low temperatures (200-300 ${ }^{\circ} \mathrm{C}$ ), i.e., (1) dissociation to isocyanate and alcohol, (2) dissociation to primary amine, olefin and carbon dioxide, and (3) elimination of carbon dioxide, leading to formation of a secondary amine. The thermal decomposition of polyurethanes is well described in the scientific literature [38-40].

Results from dynamic mechanical thermal analysis of prepared polyurethanes are presented in Fig. 11-13. Two types of relaxations are visible in the obtained results. First one, coded as $\alpha$ relaxation (with the maximum in the range from 45.8 to $68.7^{\circ} \mathrm{C}$ ) is a primary relaxation connected with the glass transition of the soft segments in the prepared poly(ether-urethane)s, while the second one is a secondary relaxation coded as a $\beta$ relaxation (with the maximum in the range from -51.1 to $-43.0{ }^{\circ} \mathrm{C}$ ). The $\beta$ relaxation was observed by several authors in the case of polyurethanes [41-43] and can be related to the molecular motions in the polyol main chains [41] and local motions of the polar urethane groups [42].
It is can be seen that the storage modulus gradually decreases above $30{ }^{\circ} \mathrm{C}$ for PU-PEG and PU-PEG/BDO, while for PU-HDO is clearly weaker above $50{ }^{\circ} \mathrm{C}$. The decreasing of storage modulus has maximum rate at the region connected with the glass transition temperature of soft segments. The glass transition temperature was determined as a temperature at which $\tan \delta$ reach maximum value. The $T_{\mathrm{gSS}}$ is $45.8{ }^{\circ} \mathrm{C}$ for PU-PEG, $53.7{ }^{\circ} \mathrm{C}$ for PU-PEG/BDO and $68.7^{\circ} \mathrm{C}$ for PU-HDO. The poly(etherurethane) synthesized using HDO as a chain extender possesses the highest glass translation temperature due to the highest cross-linking density, which is resulted from the lowest molecular weight in comparison with PEG. The introduction of poly(ethylene glycol) moieties into the structure of the polyurethanes resulted in higher mobility of polymer chains movements between fragments of structure introduced by tri-functional polyol. The chemical structure (fragments near the tri-functional polyol-based moieties) of synthesized poly(eter-urethane)s is presented earlier in Figs. 2-4. Mentioned fact caused the lowest glass transition temperature of PU-PEG. Applying a mixture of poly(ethylene glycol) with 1,4-butanediol as a chain extender of ether-urethane prepolymer resulted in higher $T_{\mathrm{g}}$ of PU-PEG/BDO in comparison with PU-PEG, due to higher restriction of polymer chains movements resulted from the presence of low molecular weight chain extender, i.e., 1,4-butanediol. The maximum values of $\tan \delta$ peaks are in a range of 1-1.2, which shows a lack of ability materials for vibration damping (absorption).

The loss modulus versus temperature of prepared polyurethanes is presented in Fig. 13. Loss modulus of materials is in the range of 335-459 MPa. The lowest value of 
Fig. 14 Cooling DSC curves of obtained poly(ether-urethane)s

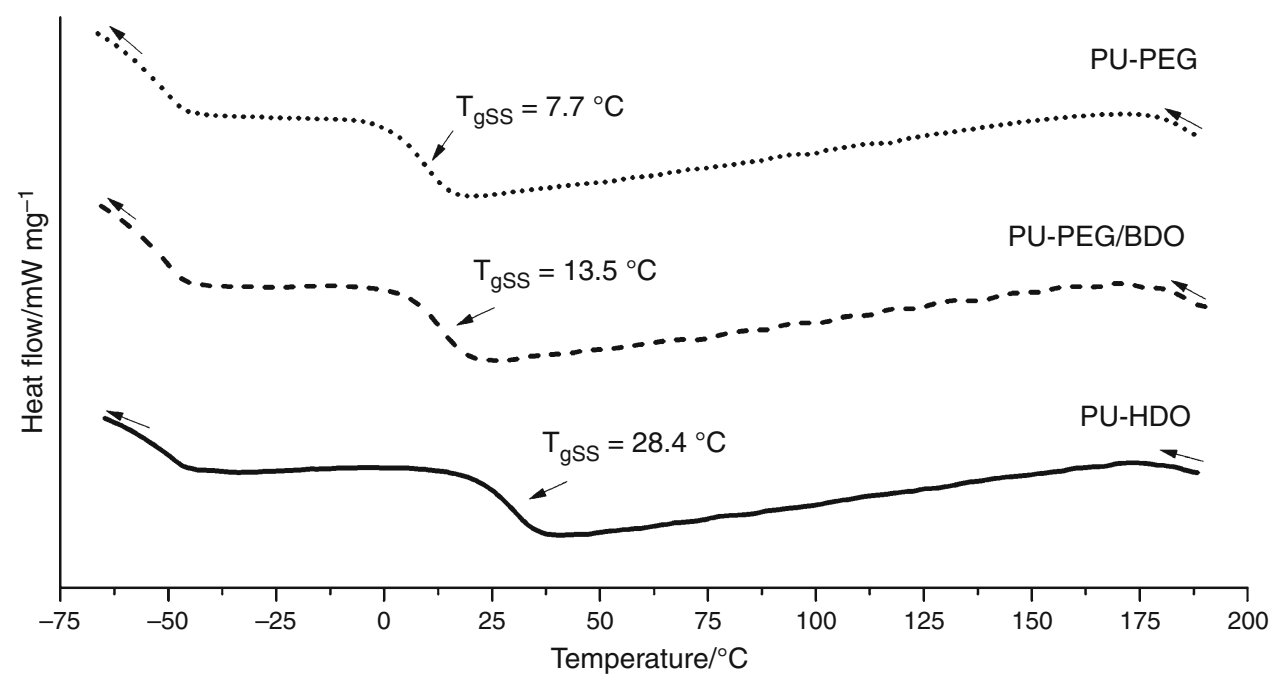

Fig. 15 Second heating DSC curves of obtained poly(etherurethane)s

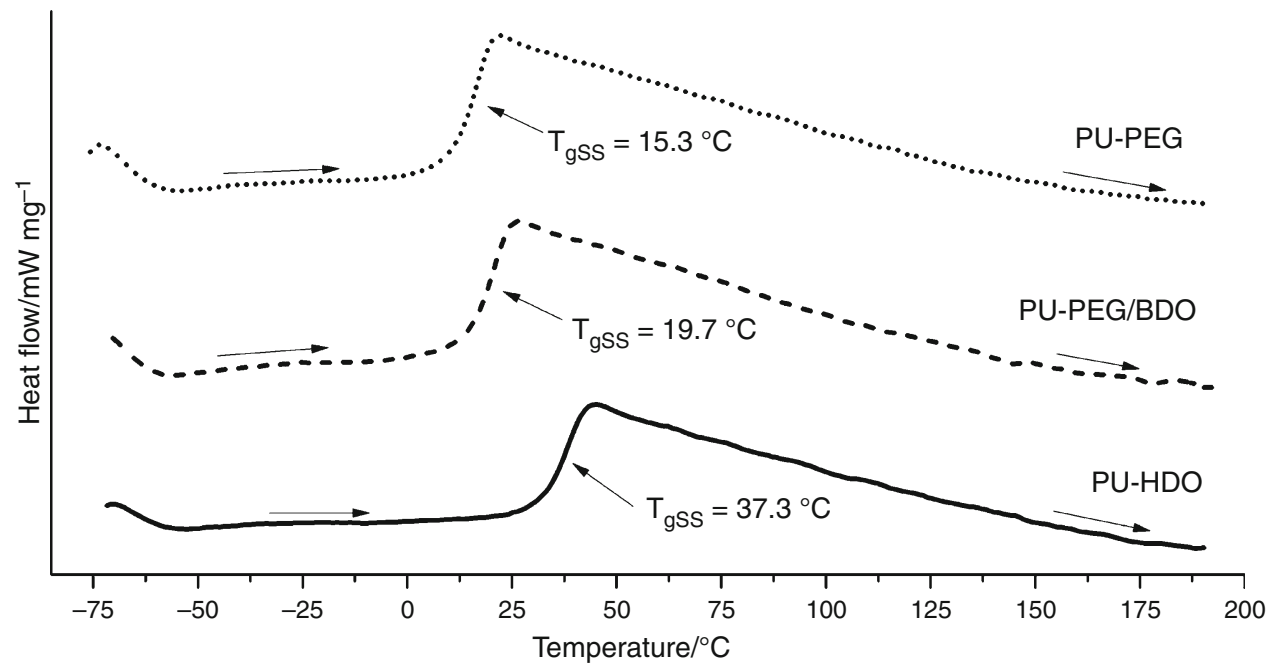

loss modulus was observed for polyurethanes obtained by using HDO as a chain extender. Loss modulus values increase with increasing content of soft segments introduced by poly(ethylene glycol) applied as a chain extender, resulting in higher energy loss.

The results of DSC analysis are presented in Table 7 and Figs. 14 and 15. The highest glass transition temperature of soft segments $\left(T_{\mathrm{gSS}}\right)$ was observed for PU-HDO-1.05. In the case of using high molecular weight chain extender as a poly(ethylene glycol), the decreasing of glass transition temperature of soft segments is observed. Recorded trends are related to the content of the hard and the soft segments in the obtained materials. Higher content of hard segments (connected with high cross-linking density) resulted in restriction of polymer chains movements and by this way affected the glass transition temperature of soft segments. The glass transition temperatures of soft segments $\left(T_{\mathrm{gSS}}\right)$ determined in the DSC study are in good correlation with DMA results.

\section{Conclusions}

The presented work showed that using tri-functional polyol and different chain extenders (with different molecular weight) allow to obtain poly(ether-urethane)s with diversified mechanical properties and similar thermal stability. The most important component, which affecting the structure and properties of obtained PUs, is tri-functional polyol, which introducing the chemical cross-links (in the soft segments) into the structure of obtained poly(etherurethane)s, so obtained materials exhibit different performance in comparison with the conventional linear polyurethane elastomers. Prepared polyurethanes exhibited the highest tensile strength, hardness and glass transition temperature, when ether-urethane prepolymer chains were extended with using low molecular weight 1,6-hexanediol. It is related to reduction of polymer chains mobility, due to higher cross-link density. The application of the high molecular weight chain extender, as poly(ethylene glycol) 
made final material more elastic, due to higher soft segments content. Moreover, introduction of PEG moieties resulted in decreasing of tensile strength and hardness. The glass transition was found to be lower, which is resulted from higher mobility of polymer chains due to the presence of long-chain extender between fragments of the structure composed from tri-functional polyol.

Open Access This article is distributed under the terms of the Creative Commons Attribution 4.0 International License (http://crea tivecommons.org/licenses/by/4.0/), which permits unrestricted use, distribution, and reproduction in any medium, provided you give appropriate credit to the original author(s) and the source, provide a link to the Creative Commons license, and indicate if changes were made.

\section{References}

1. Engels HW, Pirkl HG, Albers R, Albach RW, Krause J, Hoffmann A, Casselmann H, Dormish J. Polyurethanes: versatile materials and sustainable problem solvers for today's challenges. Angew Chem Int Ed. 2013;52(36):9422-41.

2. Nohra B, Candy L, Blanco JF, Guerin C, Raoul Y, Mouloungui Z. From petrochemical polyurethanes to biobased polyhydroxyurethanes. Macromolecules. 2013;46:3771-92.

3. Datta J, Włoch M. Progress in non-isocyanate polyurethanes synthesized from cyclic carbonate intermediates and di- or polyamines in the context of structure-properties relationship and from an environmental point of view. Polym Bull. 2016;73: 1459-96.

4. Lee A, Deng Y. Green polyurethane from lignin and soybean oil through non-isocyanate reactions. Eur Polym J. 2015;63:67-73.

5. Zhang C, Wu H, Kessler MR. High bio-content polyurethane composites with urethane modified lignin as filler. Polym (Guildf). 2015;69:52-7.

6. Datta J, Głowińska E. Effect of hydroxylated soybean oil and biobased propanediol on the structure and thermal properties of synthesized bio-polyurethanes. Ind Crops Prod. 2014;61:84-91.

7. Miyagawa H, Mohanty AK, Burgueño R, Drzal LT, Misra M. Novel biobased resins from blends of functionalized soybean oil and unsaturated polyester resin. J Polym Sci Part B Polym Phys. 2007;45(6):698-704.

8. Kim JR, Sharma S. The development and comparison of biothermoset plastics from epoxidized plant oils. Ind Crops Prod. 2012;36:485-99.

9. Ashby RD, Solaiman DKY, Strahan GD, Zhu C, Tappel RC, Nomura CT. Glycerine and levulinic acid: renewable co-substrates for the fermentative synthesis of short-chain poly(hydroxyalkanoate) biopolymers. Bioresour Technol. 2012;118:272-80.

10. Teramoto N, Saitoh Y, Takahashi A, Shibata M. Biodegradable polyurethane elastomers prepared from isocyanate-terminated poly(ethylene adipate), castor oil, and glycerol. J Appl Polym Sci. 2010;115:3199-204.

11. Firdaus M, Montero De Espinosa L, Meier MAR. Terpene-based renewable monomers and polymers via thiol-ene additions. Macromolecules. 2011;44:7253-62.

12. Atta AM, El-Saeed SM, Farag RK. New vinyl ester resins based on rosin for coating applications. React Funct Polym. 2006;66:1596-608.

13. Atta AM, Elsaeed AM, Farag RK, El-Saeed SM. Synthesis of unsaturated polyester resins based on rosin acrylic acid adduct for coating applications. React Funct Polym. 2007;67:549-63.
14. Gurunathan T, Mohanty S, Nayak SK. Isocyanate terminated castor oil-based polyurethane prepolymer: synthesis and characterization. Prog Org Coat. 2015;80:39-48.

15. Xu Y, Petrovic Z, Das S, Wilkes GL. Morphology and properties of thermoplastic polyurethanes with dangling chains in ricinoleate-based soft segments. Polymer. 2008;49:4248-58.

16. Liu W, Xu K, Wang C, Qian B, Sun Y, Zhang Y, Xie H, Cheng R. Carbon nanofibers reinforced soy polyol-based polyurethane nanocomposites. J Therm Anal Calorim. 2016;123:2459-68.

17. Surender R, Mahendran AR, Wuzella G, Vijayakumar CT. Synthesis, characterization and degradation behavior of thermoplastic polyurethane from hydroxylated hemp seed oil. J Therm Anal Calorim. 2016;123:525. doi:10.1007/s10973-015-4856-x.

18. Piszczyk Ł, Strankowski M, Danowska M, Hejna A, Haponiuk JT. Rigid polyurethane foams from a polyglycerol-based polyol. Eur Polym J. 2014;57:143-50.

19. Calvo-Correas T, Santamaria-Echart A, Saralegi A, Martin L, Valea Á, Corcuera MA. Thermally-responsive biopolyurethanes from a biobased diisocyanate. Eur Polym J. 2015;70:173-85.

20. Oprea S. Structure and properties of cross-linked polyurethane copolymers. Adv Polym Technol. 2009;28:165-72.

21. Waterlot V, Couturier D, Waterlot C. Structure and physical properties in crosslinked polyurethanes. J Appl Polym Sci. 2011;119:1742-51.

22. Buckley CP, Prisacariu C, Caraculacu A. Novel triol-crosslinked polyurethanes and their thermorheological characterization as shape-memory materials. Polymer. 2007;48:1388-96.

23. Heinen M, Gerbase AE, Petzhold CL. Vegetable oil-based rigid polyurethanes and phosphorylated flame-retardants derived from epoxydized soybean oil. Polym Degrad Stab. 2014;108:76-86.

24. Narine SS, Kong X, Bouzidi L, Sporns P. Physical properties of polyurethanes produced from polyols from seed oils: I. Elastomers. J Am Oil Chem Soc. 2007;84:55-63.

25. Piszczyk Ł, Strankowski M, Danowska M, Haponiuk JT, Gazda M. Preparation and characterization of rigid polyurethane-polyglycerol nanocomposite foams. Eur Polym J. 2012;48:1726-33.

26. Luo X, Hu S, Zhang X, Li Y. Thermochemical conversion of crude glycerol to biopolyols for the production of polyurethane foams. Bioresour Technol. 2013;139:323-9.

27. Raquez J-M, Deléglise M, Lacrampe M-F, Krawczak P. Thermosetting (bio)materials derived from renewable resources: A critical review. Prog Polym Sci. 2010;35:487-509.

28. Gustini L, Noordover BAJ, Gehrels C, Dietz C, Koning CE. Enzymatic synthesis and preliminary evaluation as coating of sorbitol-based, hydroxy-functional polyesters with controlled molecular weights. Eur Polym J. 2015;67:459-75.

29. Anand A, Kulkarni RD, Gite VV. Preparation and properties of eco-friendly two pack PU coatings based on renewable source (sorbitol) and its property improvement by nano $\mathrm{ZnO}$. Prog Org Coat. 2012;74:764-7.

30. Chen K, Leon YT, Chen Y, Chen YS, Lin TL, Liu WJ. Soft-and hard-segment phase segregation of polyester-based polyurethane. J Polym Res. 2001;8:99-109.

31. Saha C, Chaki TK, Singha NK. Synthesis and characterization of elastomeric polyurethane and PU/clay nanocomposites based on an aliphatic diisocyanate. J Appl Polym Sci. 2013;130:3328-34.

32. Pawlik H, Prociak A. Influence of palm oil-based polyol on the properties of flexible polyurethane foams. J Polym Environ. 2012;20:438-45.

33. Kucińska-Lipka J, Gubańska I, Sienkiewicz M. Thermal and mechanical properties of polyurethanes modified with L-ascorbic acid. J Therm Anal Calorim. 2016;. doi:10.1007/s10973-016-5743-9.

34. Ciecierska E, Jurczyk-Kowalska M, Bazarnik P, Kowalski M, Krauze S, Lewandowska M. The influence of carbon fillers on the thermal properties of polyurethane foam. J Therm Anal Calorim. 2016;123:283-91. 
35. Dyer E, Newborn GE. Thermal degradation of carbamates of methylenebis-(4-phenyl Isocyanate). J Am Chem Soc. 1958;80: 5495-8.

36. Dyer E, Wright GC. Thermal degradation of alkyl N-phenylcarbamates. J Am Chem Soc. 1959;81:2138-43.

37. Dyer E, Read RE. Thermal degradation of O-1-hexadecyl N-1naphthylcarbamates and related compounds. J Org Chem. 1961;26:4388-94.

38. Voorhees KJ, Hileman FD, Einhorn IN, Futrell JH. An investigation of the thermolysis mechanism of model urethanes. J Polym Sci A Polym Chem. 1978;16:213-28.

39. Font R, Fullana A, Caballero JA, Candela J, Garcia A. Pyrolysis study of polyurethane. J Anal Appl Pyrol. 2001;58-59:63-77.

40. Ravey M, Pearce EM. Flexible polyurethane foam. I. Thermal decomposition of a polyether-based, water-blown commercial type of flexible polyurethane foam. J Appl Polym Sci. 1997;63: 47-74.
41. Javni I, Zhang W, Petrović ZS. Effect of different isocyanates on the properties of soy-based polyurethanes. J Appl Polym Sci. 2003;88:2912-6.

42. Czech P, Okrasa L, Ulanski J, Boiteux G, Mechin F, Cassagnau P. Studies of the molecular dynamics in polyurethane networks with hyperbranched crosslinkers of different coordination numbers. J Appl Polym Sci. 2007;105:89-98.

43. Harris RF, Joseph MD, Davidson C. Polyurethane elastomers based on molecular weight advanced poly(ethylene ether carbonate) polyols. IV. Effects of poly(propylene glycol) modified diols. J Appl Polym Sci. 1992;46:1843-57. 